\title{
RELATIONSHIP BETWEEN NEUTROPHIL - LYMPHOCYTE RATIO AND DECREASED GLOMERULAR FILTRATION RATE IN DIABETIC
}

\author{
Asriyani Azikin, Fitriani Mangarengi, Uleng Bahrun
}

Department of Clinical Pathology, Faculty of Medicine, Hasanuddin University, Makassar. E-mail: asriyaniazikin@gmail.com

\begin{abstract}
Diabetic nephropathy is one of the fairly severe Diabetes Mellitus (DM) complications and the main cause of renal failure that can result in mortality. Hyperglycemia in DM induces kidney injury that may result in hemodynamic and metabolic alterations, endothelial dysfunction and inflammatory cells activation. A persistent and continuous inflammation is observed in diabetic nephropathy. One of the inflammation process progression indicators is Neutrophil-Lymphocyte Ratio (NLR). To find out the relationship between NLR and decreased Glomerular Filtration Rate (GFR) in diabetic nephropathy. This study was an observational study with a retrospective approach. This study was conducted in Clinical Pathology Laboratory Installation and Medical Record Installation of Dr. Wahidin Sudirohusodo Makassar Hospital by collecting the patient's data during February 2015 to February 2016. Patients that were diagnosed as type 2 DM without diabetic nephropathy complication were taken as control and those diagnosed as type 2 DM with diabetic nephropathy were treated as study subjects. One hundred and thirteen (113) samples met the inclusion criteria, consisting of 73 diabetic nephropathy patients with Chronic Kidney Disease (CKD) 13 diabetic nephropathy patients without CKD and 27 type 2 DM patients without diabetic nephropathy complication. Patients consisted of 57 males (50.4\%) and 56 females (49,6\%). Neutrophil-lymphocyte ratio and GFR values in the group of diabetic nephropathy without CKD were $2.03 \pm 0.68$ and $85.38 \pm 24.63$, respectively. Whereas, the NLR and GFR values in control group were $1.74 \pm 0.54$ and $90.03 \pm 28.60$, respectively. In the group of diabetic nephropathy with CKD, NLR value increased by $3.19 \pm 1.83$ and GFR decrease by $30.54 \pm 16.45$. Spearman test indicated a significant relationship between NLR increase and decreased GFR $(r=-0.635, p=0.00)$. There is a significant relationship between NLR increase and decreased GFR in patients with diabetic nephropathy.
\end{abstract}

Keywords: Neutrophil-lymphocyte ratio, glomerular filtration rate, diabetic nephropathy, chronic kidney disease

\section{INTRODUCTION}

Diabetic nephropathy is a microvascular complication of Diabetes Mellitus (DM), particularly the type 2 DM. In some patients, this complication develops into Chronic Kidney Disease (CKD) and ultimately results in terminal renal failure that requires hemodialysis and renal transplantation. The Indonesian Nephrology Association (PERNEFRI) stated in 1995 that diabetic nephropathy ranks number 3 (16.1\%) following chronic glomerulonephritis (30.1\%) and chronic pyelonephritis (17.51\%) as the cause of renal failure that requires hemodialysis in Indonesia. According to the Microalbuminuria Prevalence Study (MAPS) in 2004, there were almost $60 \%$ of nephropathy. ${ }^{1,2}$

There are five phases of development towards diabetic nephropathy: Phase I, hyperfiltration with increased glomerular filtration rate (GFR), no evident albuminuria and renal hypertrophy (histopatologic); Phase II, relatively normal albumin excretion $1<30$ $\mathrm{mg} / 24$ hours), albumin increases after physical exercise,and stressful condition, perpetuated renal structural change, with high risk to develop into diabetic nephropathy; Phase III, the initial phase of diabetic nephropathy, evident microalbuminuria (30$300 \mathrm{mg} / 24$ hours), GFR remains high or can be normal, histopatologically there is a swelling in glomerular basal membran; Phase IV, proteinuria is 
acquired, albumin excretion $>300 \mathrm{mg} / 24$ hours, there is a decrease in GFR and usually accompanied by hypertension; Phase $\mathrm{V}$, the End Stage Renal Disease (ESRD) in which GFR has been very low and indicates signs of uremia. ${ }^{3,4}$

Factors involved in the development of diabetic nephropathy include genetic factor, glomerular hyperfiltration, oxidative stress, Advanced Glycation End Product (AGE) activation, protein kinase activation, excessive expression of transforming growth-factor- $\beta$ (TGF- $\beta$ ), followed by increased extracellular matrix playing role in the emergence of vascular complication including diabetic nephropathy. Hyperglycemia triggers the occurrence of renal damage that can result in hemodynamic changes, metabolic changes, endothelial dysfunction, altered vascular factor expression resulting in inflammatory cell activation (increased white blood cells including neutrophils). Persistent and perpetuated inflammation occur in diabetic nephropathy, there is an increase in inflammatory mediators including Interleukin-1 (IL-1), Interleukin 6 (IL-6), interferon- $\gamma$ and Tumor Necrosing Factor- $\alpha$ (TNF- $\alpha$ ) that accelerate muscular protein catabolism, increase positive synthesis of acute-phase protein C-reactive Protein (CRP) and suppress protein/albumin production, in addition to the protein disappearance through proteinuria. Hematopoiesis requires adequate nutrition, as protein deficiency alters the bone marrow function, implicating in lymphocyte neutrophil insufficiency. Increased neutrophils and decreased lymphocytes cause the Neutrophil-Lymphocyte Ratio (NLR) to increase. Therefore, NLR can be a marker for a systemic inflammatory process. ${ }^{3,5-7}$

The neutrophil is a polymorphonuclear mature granular leukocyte that has the affinity to immune complex and phagocytosis, whereas the lymphocyte plays a role as a specific immune system and targeting specific antigens which are its ligands. Also, the specific immune response also causes immunologic memory that will react fast when the host is reexposed to the same antigen in the future. In acquired immunity, antibodies and effector lymphocytes that are specific to their stimulating antigen will be formed causing antigen elimination. ${ }^{8}$

Neutrophil-lymphocyte ratio is useful as an indicator of inflammatory process progress in various diseases such as appendicitis, cardiac diseases and cancers. This neutrophil-lymphocyte ratio is also used as an inflammation marker in diabetic nephropathy. $^{9}$

\section{METHODS}

This study was a retrospective study that collected secondary data of patients diagnosed with diabetic nephropathy and patients type 2 Diabetes Mellitus without diabetic nephropathy complication as control from the Medical Record Installation of Dr. Wahidin Sudirohusodo Hospital during February 2015 to February 2016. Inclusion criteria were adult patients aged 35-85 years-old diagnosed with type 2 DM with diabetic nephropathy and patients with type 2 DM without diabetic nephropathy (as controls) who were routinely evaluated for hematology and differential cell count starting from day 1 of admission to the Dr. Wahidin Sudirohusodo Hospital, Makassar.

Diabetic nephropathy was established when the following requirements were met: ${ }^{4} \mathrm{DM}$; There is persistent proteinuria for two evaluations with two weeks interval without other proteinuria cause, or proteinuria for one evaluation with serum creatinin level $>2.5 \mathrm{mg} / \mathrm{dL}$. Whereas, the clinical stage diagnosis of diabetic nephropathy was classically established based on the presence of proteinuria $>0.5$ gr/day.

Neutrophil-lymphocyte ratio as the result of neutrophil absolute count divided by lymphocyte absolute count in diabetic nephropathy patients in $10^{3} / \mathrm{mL}$ unit which was obtained from routine hematology results using $\mathrm{K}_{3}$ EDTA blood sample and measured by flowcytometry with Sysmex XT-2000i. Glomerular filtration rate was measured according to Cockroft-Gault formula. Type $2 \mathrm{DM}$ patients with GFR $<60 \mathrm{~mL} / \mathrm{min}$ (corresponding to CKD grade 3, 4 and 5 according to The National Kidney Foundation Guideline) were assigned to diabetic nephropathy with CKD group and diabetic nephropathy patients with GFR $\geq 60$ were assigned to non-CKD diabetic nephropathy group. Data were analyzed statistically to assess the NLR distribution in GFR decrease. When the data were not normally distributed, analysis with Saphiro-Wilk Test was performed. When normally distributed, data were analyzed by Mann-Whitney and Spearman correlation. 


\section{RESULTS AND DISCUSSION}

This study was conducted on 113 subjects with diagnosed type $2 \mathrm{DM}$ and diabetic nephropathy who met the inclusion criteria with characteristics as shown in Table 1. Study subjects consisted of 73 diabetic nephropathy patients with CKD, 13 diabetic nephropathy patients without CKD, 27 type 2 DM patients without diabetic nephropathy complication. The number of male subjects (50.4\%) and female subjects (49.6\%) was similar.

Table 1. Distribution/data of study group characteristics

\begin{tabular}{|c|c|c|}
\hline Subject characteristic & $\begin{array}{l}\text { Frequency } \\
\text { (n) }\end{array}$ & $\begin{array}{c}\text { Percentage } \\
(\%) \\
\end{array}$ \\
\hline \multicolumn{3}{|l|}{ Sex } \\
\hline Male & 57 & 50.4 \\
\hline Female & 56 & 49.6 \\
\hline \multicolumn{3}{|l|}{ Type of DM } \\
\hline $\begin{array}{l}\text { Diabetic nephropathy } \\
\text { with CKD }\end{array}$ & 73 & 64.6 \\
\hline $\begin{array}{l}\text { Type } 2 \text { DM without } \\
\text { diabetic nephropathy }\end{array}$ & 27 & 23.9 \\
\hline $\begin{array}{l}\text { Diabetic nephropathy } \\
\text { without CKD }\end{array}$ & 13 & 11.5 \\
\hline \multicolumn{3}{|l|}{ GFR decrease rate } \\
\hline $\begin{array}{l}\text { Normal or increased } \\
\text { GFR }\end{array}$ & 18 & 15.9 \\
\hline $\begin{array}{l}\text { Normal or slightly } \\
\text { decreased GFR }\end{array}$ & 20 & 17.7 \\
\hline $\begin{array}{l}\text { Moderate GFR decrease } \\
\text { type A }\end{array}$ & 20 & 17.7 \\
\hline $\begin{array}{l}\text { Moderate GFR decrease } \\
\text { type B }\end{array}$ & 18 & 15.9 \\
\hline Severe GFR decrease & 22 & 19.5 \\
\hline Renal failure & 15 & 13.3 \\
\hline Total & 113 & 100 \\
\hline
\end{tabular}

Table 2 showed that there was no significant difference in body weight, leukocytes and fasting blood glucose level between the three study groups. Significant differences were observed for creatinine value, ureum, neutrophils, lymphocytes, neutrophil/ lymphocyte ratio and GFR between diabetic nephropathy with CKD group, diabetic nephropathy without CKD group and control group (type $2 \mathrm{DM}$ without diabetic nephropathy complication), all with $p$-value $p=0.000$.

This study found that the proportion of male (50.4\%) and female (49.6\%) subjects in each group was almost equal. According to Table 1 , the number of subjects who met the inclusion criteria was 113, consisting of 73 diabetic nephropathy with CKD, 13 diabetic nephropathies without CKD and 27 type 2 DM without diabetic nephropathies complication

This study found that neutrophils in diabetic nephropathy with CKD $(5.818 \pm 2.013)$ were higher compared to nephropathy without CKD $(5.726 \pm 1.736)$ and control (5.288 \pm 1.094). The persistent inflammatory process in diabetic nephropathy caused neutrophils activation. IL- 6 as one of the released inflammatory mediator is capable of stimulating neutrophil production from progenitor cells called Colony Stimulating Factor (CSF) in bone marrow. Neutrophil will adhere to the target cell, namely the endothelial cells in blood vessels, resulting in disturbed endothelial function in blood vessels. ${ }^{1,10}$

Lymphocyte count in diabetic nephropathy with CKD group $(2.064 \pm 0.890)$ tended to be lower compared to nephropathy without CKD (3.000 \pm 0.679$)$ and control (3.109 \pm 0.977). Persistent and perpetuated inflammation occur in diabetic nephropathy so, there is an increase in inflammatory mediators such as Interleukin (IL)-1, IL-6, interferon- $\gamma$ and Tumor Necrosing Factor- $\alpha$ (TNF- $\alpha$ ) that accelerates the muscular protein catabolism, increases positive stenosis of acute-phase protein C-reactive protein (CRP) and suppresses protein/albumin production, in addition to the loss of protein through proteinuria. Hematopoiesis needs adequate nutrition, so the protein deficiency alters the bone marrow function, resulting in insufficient lymphocytes, leptin and IL-6 produced by adipose tissue in type 2 DM patient. Leptin inhibition against T helper 2 (Th2) proliferation will cause the lymphocyte count to decrease. A study by Nakhjavani in DM patients with CKD found the higher neutrophil and monocyte count and lower lymphocyte count compared to DM patients without CKD in 2014. ${ }^{7,10-12}$

In the present study, the NLR value in control group was $1.74 \pm 0.54$, with a GFR value $90.03 \pm 28.60$. In diabetic nephropathy without CKD group, NLR value increased to $2.03 \pm 0.68$, but the GFR value decreased to $85.38 \pm 24.63$. In diabetic nephropathy with CKD group, the NLR value increased to $3.19 \pm 1.83$ followed by a decreased GFR to $30.54 \pm 16.45$. Study results indicated that there was a relationship between neutrophil-lymphocyte ratio and decreased GFR with the coefficient of correlation of -0.635 and coefficient of determination of 0.403 , meaning that each increase in NLR will be followed by a GFR decrease by $40 \%$. The result is in accordance with a study by Nakhjavani that NLR was a good predictor for decreased GFR in a 
patient with type 2 DM in 2014, in the Department of between neutrophil, monocyte and lymphocyte in Endocrinology and Metabolism, University of Tehran, type 2 DM patients with microalbuminuria in 2007 at Iran. ${ }^{10}$ the Dr Kariadi Hospital, Semarang

Table 2.Characteristic difference and measurement of study group subjects data

\begin{tabular}{|c|c|c|c|c|}
\hline Measurement of subjects data & $\begin{array}{c}\text { Diabetic nephropa- } \\
\text { thy with CKD }\end{array}$ & $\begin{array}{c}\text { Diabetic nephropathy } \\
\text { without CKD }\end{array}$ & Control & p-value \\
\hline Age (year) & $58.58 \pm 8.48^{b}$ & $53.77 \pm 6.68^{b}$ & $63.63 \pm 9.74$ & $0.003 *$ \\
\hline Body weight (kg) & $61.28 \pm 9.70$ & $61.38 \pm 10.08$ & $64.96 \pm 10.76$ & 0.346 \\
\hline Creatinine $(\mathrm{mg} / \mathrm{dL})$ & $2.85 \pm 1.77^{\mathrm{a}, \mathrm{b}}$ & $0.85 \pm 0.27$ & $0.97 \pm 1.02$ & $0.000 *$ \\
\hline Ureum (mg/dL) & $77.67 \pm 38.31^{a, b}$ & $29.38 \pm 9.85$ & $25.48 \pm 7.58$ & $0.000 *$ \\
\hline Leuocytes $\left(10^{3} / \mathrm{mL}\right)$ & $8.735 \pm 2.213$ & $8.730 \pm 1.694$ & $8.422 \pm 1.986$ & 0.615 \\
\hline Neutrophils $\left(10^{3} / \mathrm{mL}\right)$ & $5.818 \pm 2.013^{\mathrm{a}, \mathrm{b}}$ & $5.726 \pm 1.736$ & $5.288 \pm 1.094$ & $0.000 *$ \\
\hline Lymphocytes $\left(10^{3} / \mathrm{mL}\right)$ & $2.064 \pm 0.890^{a, b}$ & $3.000 \pm 0.679$ & $3.109 \pm 0.977$ & $0.000 *$ \\
\hline Fasting glucose level (mg/dL) & $184.39 \pm 71.55$ & $142.07 \pm 67.42$ & $181.40 \pm 78.50$ & 0.092 \\
\hline GFR (mL/min) & $30.54 \pm 16.45^{a, b}$ & $85.38 \pm 24.63$ & $90.03 \pm 28.60$ & $0.000 *$ \\
\hline NLR & $3.19 \pm 1.8^{a, b}$ & $2.03 \pm 0.68$ & $1.74 \pm 0.54$ & $0.000 *$ \\
\hline
\end{tabular}

Normality test, Shapiro-Wilk test: $p<0.05$; data distribution not normal

*Kruskal Wallis test: $p<0.05$; significant

aPost hoc test:Mann Whitney U-test; $\mathrm{p}<0.05$; significantly different with “Diabetic nephropathy without CKD" group

${ }^{b}$ Post hoc test:Mann Whitney U-test; $p<0.05$; significantly different with "Diabetes Mellitus have not developed diabetic nephropathy" group

Table 3. Correlation between neutrophil-lymphocyte ratio and GFR reduction in each study group

\begin{tabular}{lcccc}
\hline \multicolumn{1}{c}{ Study group } & NLR & GFR & p-value & r $/ \mathbf{r}^{2}$ \\
\cline { 2 - 3 } & Mean \pm SD & Mean \pm SD & & $-0.165 / 0.027$ \\
Type 2 DM without diabetic nephropathy & $1.74 \pm 0.54$ & $90.03 \pm 28.60$ & & 0.410 \\
Diabetic nephropathy without CKD & $2.03 \pm 0.68$ & $85.38 \pm 24.63$ & 0.504 & $-0.204 / 0.041$ \\
Diabetic nephropathy with CKD & $3.19 \pm 1.83$ & $30.54 \pm 16.45$ & $0.000^{*}$ & $-0.486 / 0.236$ \\
Overall & $2.71 \pm 1.64$ & $51.06 \pm 34.73$ & $0.000^{*}$ & $-0.635 / 0.403$ \\
\hline
\end{tabular}

Normality test, Shapiro-Wilk test: $\mathrm{p}<0.05$; data distribution not normal

*Spearman's rho test: $p<0.05$; significant

Study findings indicated that there was no significant difference between NLR and GFR in diabetic without nephropathy group $(p=0.410)$ and diabetic nephropathy without CKD group ( $p=0.504)$. These findings were in accordance with a study by Purwanto showing that there was no correlation, ${ }^{1}$

\section{CONCLUSION AND SUGGESTION}

There was a relationship between an increase in NLR and GFR decrease in diabetic nephropathy patients with CKD. Study samples should be larger than the present study so that the results of the study could be more representative to compare the correla- 
tion between the increase of NLR and decrease of GFR in two groups such as diabetic nephropathy without CKD and diabetic nephropathy with CKD.

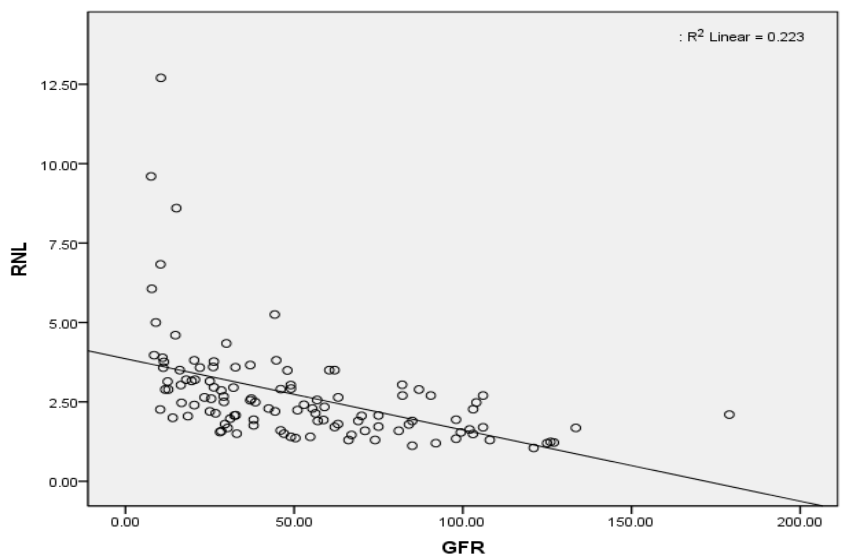

Figure 1. The relationship between neutrophil ymphocyte ratio and glomerular filtration rate

\section{REFERENCES}

1. Purwanto Edi. korelasi jumlah neutrofil, limfosit, dan monosit dengan kadar albumin urin pada pasien $\mathrm{dm}$ tipe-2. Department of Clinical Pathology Science of Diponegoro University. Jurnal Biomedika. 2009;1(1): 7-17

2. American diabetes association. hypertension management in adults with diabetic. Diabetic Care). 2004; (Suppl 1): 65-67.

3. Shikata K, Makino H. microinflammation in the pathogenesis of diabetic nephropathy in journal of diabetes investigation. Asian Association for Study of Diabetes and Wiley Publishing Asia Ltd. 2013; 4(1): 142-149.

4. Lestaningsih. hipertensi pada diabetik PIT V, PERKENI. Semarang, 2004; $1-5$.
5. Lim AK, tesch gh. review article: inflammation in diabetic nephropathy. Hindawi Publishing Corporation Mediators Inflammation Journal, 2012; 2012(1): 146154.

6. Lubis HR. penyakit ginjal diabetik dalam ilmu ajar penyakit dalam. $5^{\text {th }}$ Ed., $2^{\text {nd }}$ bundle. Jakarta, Interna publishing. 2009; 979-982.

7. Kato $S, A$ be $T$, lindholm b. neutrophil lymphocyte ratio a promising prognostic marker in patients with chronic kidney disease. Inflammation and Cell Signaling, 2015; 1-5. Available at:http;//www. Smartscitech.com/ index.php/ics.

8. Abbas AK, Litchman AH. Basic Immunology. $3^{\text {rd }}$ Ed Updated., Philadelphia, The United States of America, Saunder Elsevier. 2011; 27-54.

9. Zahorec R. ratio of neutrophil to lymphocyte counts rapid and simple parameter of systemic inflammation and stress in critically ill. Dept. of Anaesthesia and Intensive Care Medicine. Slovakia. 2001; 102(1):5-14

10. Nakhjavani M, Aghajani AN, Salabati M, Mahmoudzadeh R, Morteza A, et al. changes in leucocyte subpopulation with declined glomerular filtration rate in patients with type 2 diabetes. department of endocrinology, endocrinology and metabolism research center, Tehran University. Iran, Acta Medica Iranica, 2015; 53 (7): 425-431.

11. Akbas EM, Demirtas L, Ozcicek A, Timuroglu A, Murat $E$, et al. association of epicardial adipose tissue, neutrophil to lymphocyte ratio and platelet to lymphocyte ratio with diabetic nephropathy. Department of Endocrinology, Internal Medicine, Nephrology, Erzinchan University. Turkey, International Journal of Clinical and Experimental Medicine, 2014; 7(7):1794-1801.

12. Covacs LG. Diabetic Nephropathy in New Trend in Classification, diagnosis and management of kidney diseases. division of nephrology, department of internal medicine. Clinical Hospital Merkur Zagreb Croatia. 2008; 1 -9. 